\title{
Power Efficiency Improvement of a Multi-Oscillated Current Resonant Type DC-DC Converter
}

\author{
Tadahiko-SATO $^{1,2}$, Hirofumi-MATSUO ${ }^{2}$, Hiroyuki-OTA $^{1}$, Yoichi-ISHIZUKA ${ }^{2}$ and Nobuhiro-HIGASHI ${ }^{1}$ \\ ${ }^{1}$ Fuji Electric Device Technology Co., Ltd. \\ ${ }^{2}$ Graduate School of Science and Technology, Nagasaki University \\ E-mail: sato-tadahiko@fujielectric.co.jp
}

\begin{abstract}
This paper deals with an improvement of a power efficiency of a multi-oscillated current resonant type DC-DC converter. The current resonant type converter employs generally the pulse frequency modulation and its magnetizing inductance is set relatively low. For this reason, the magnetizing current through the converter causes a power loss under a light load. In order to solve this problem, a multi-oscillated current resonant type DC-DC converter has been proposed, and revealed the advantage of its control method which can reduce power loss under light load and keep low switching noise. In this topology, output power is controlled by duty ratio and operating frequency is determined by resonant condition.

In this paper, an analysis of power loss by focusing on switching devices in this converter to improve power efficiency was given. As a result, it was confirmed that the loss of diodes in secondary side occupies main loss. Adopting the synchronous rectifier in the secondary side, the maximum power efficiency is improved to $96.3 \%$, and the average efficiency, which is averaged efficiency at $25 \%, 50 \%, 75 \%$ and $100 \%$ of the rated load, reached $95.5 \%$.
\end{abstract}

\section{INTRODUCTION}

A switching power supply system with the high efficiency, small size, low noise and low cost, is required in many areas of not only consumer electronics but also telecommunication systems such as personal computers, cellular phones, flat panel displays and so forth. Recently, keeping to high efficiency from the light load to the rated load is more important from the point of energy savings considering actual operating condition of the power supply.

The current resonant type converters make practicable because of high efficiency and low noise. Generally the pulse frequency modulation (PFM) is applied to the current resonant type converters $[1,2]$. However, this type of converter has problem, in which a magnetizing current through the converter causes a loss of power under the light load. Consequently, it is hard to improve average efficiency from the light load to the rated load.

In order to solve these problems, a multi-oscillated current resonant type DC-DC converter has been proposed [3, 4].

It has been clarified in recent investigation that maximum output power is depend on the energy charged in resonant capacitor [5, 6]. In addition, as an analysis of power efficiency, analyzed from the viewpoint of the duty ratio and a through current in primary and secondary sides [7].
This paper presents an analysis of power loss by focusing on switching devices in a Multi-Oscillated Current Resonant Type DC-DC Converter, and an improvement of power efficiency by using synchronous rectifier on the secondary side.

\section{CIRCUIT CONFIGURATION AND OPERATING PRINCIPLE}

Fig. 1 and 2 show the proposed multi-oscillated current resonant DC-DC converter and the timing chart, respectively. This converter consists of a half-bridge circuit, whose switches $\mathrm{Q}_{1}$ and $\mathrm{Q}_{2}$ which consist of MOSFET, are operated by a multi-oscillated current resonant driven by an IC with pulse-width modulation (PWM), and an auxiliary winding $\mathrm{N}_{\mathrm{P} 2}$ of the transformer, respectively.

By applying a gate voltage to $\mathrm{Q}_{1}$ and $\mathrm{Q}_{2}$ at turn-on and turnoff, switching power losses are reduced due to the zerovoltage switching (ZVS) and zero-current switching (ZCS). In the isolated transformer $T_{r}$, the primary winding $N_{P 1}$ is loosely coupled to the secondary windings $\mathrm{N}_{\mathrm{S} 1}$ and $\mathrm{N}_{\mathrm{S} 2}$, for in which the voltage of the leakage inductance is relatively large. Because of the resonant circuit with this leakage inductance and the resonant capacitor, the switching power losses of $\mathrm{Q}_{1}$ and $\mathrm{Q}_{2}$ are reduced.

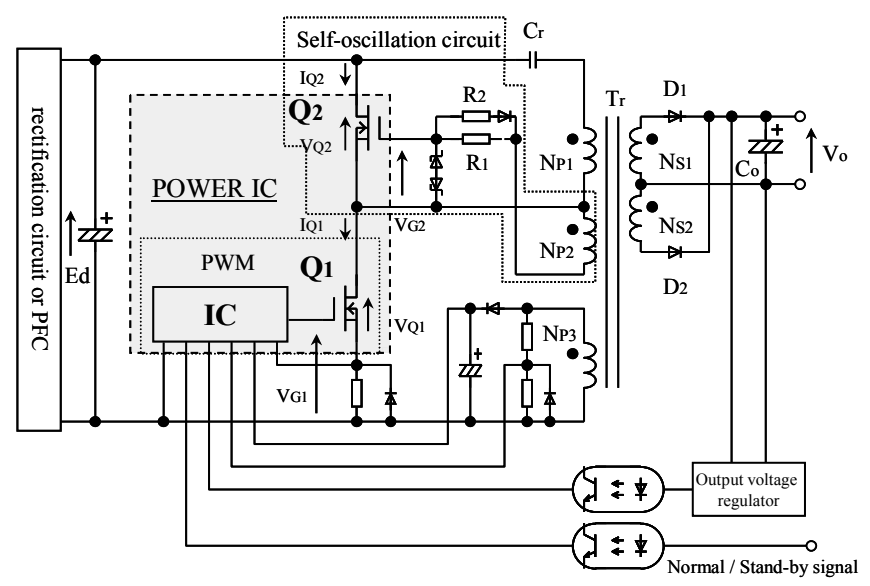

Fig. 1 Circuit configuration 


\section{ANALYSIS OF STATES AND OPERATING MODES}

Fig. 3 shows the equivalent circuits of the converter shown in Fig. 1, which is divided into eight behavior states. Taking into account the combination of the eight states of behavior, they are further divided into four operating modes [5-7].

Fig.4 shows the simulated waveforms of the current and voltage for the four operating modes. From the results, the operating modes appear in the order of I, II, III and IV when the load current is varied from a light load to the heavy load.

The operating modes I and II mainly appear at light load. The energy in $\mathrm{C}_{\mathrm{r}}$ is discharged when the $\mathrm{Q}_{1}$ turns off and $\mathrm{Q}_{2}$ turns on, and charged by applying the output voltage $\mathrm{E}_{\mathrm{d}}$ of the $\mathrm{PFC}$ when the $\mathrm{Q}_{1}$ turns on and $\mathrm{Q}_{2}$ turn off. Therefore, the energy is discharged to the secondary side through the transformer. However, because of the magnetizing inductance $\mathrm{L}_{\mathrm{m}}$ is set relatively large when there is shortage of the energy discharged from $\mathrm{C}_{\mathrm{r}}$, operating state 7 appears, in which there is no discharging interval to the secondary side.

In mode III, a ripple is reduced and smoothed by the leakage inductance $\mathrm{L}_{12}$ of the secondary winding and the output capacitor $\mathrm{C}_{\mathrm{o}}$ because the current flows continuously through $\mathrm{D}_{1}$ and $\mathrm{D}_{2}$, alternately.

The Mode IV appears when the duty ratio is almost over $50 \%$. In this mode, the state 8 appear where the power is not applied to the secondary side even when $\mathrm{Q}_{1}$ turns on.

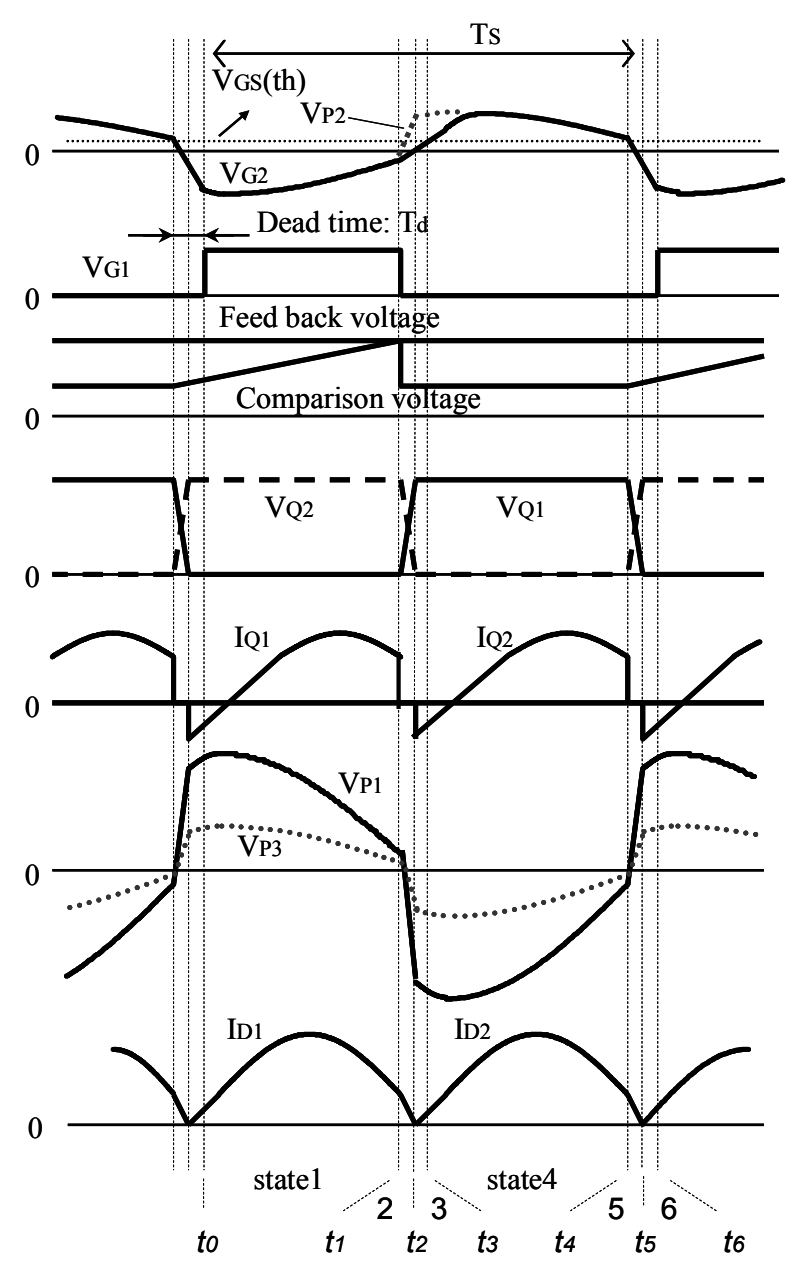

Fig. 2 Timing chart

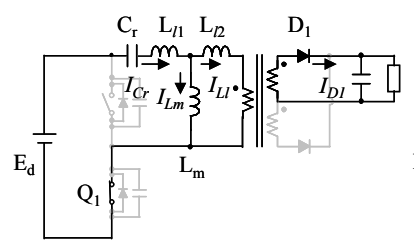

(a) State1

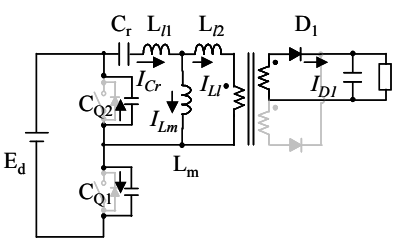

(b) State2

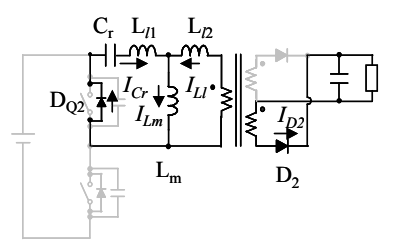

(c) State3

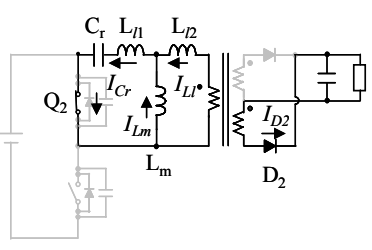

(d) State4

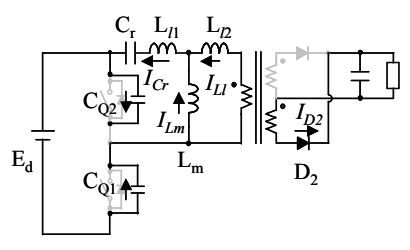

(e) State5

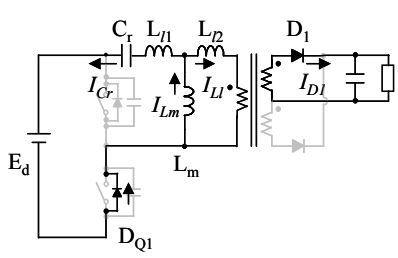

(f) State6

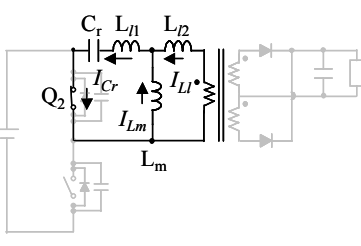

(g) State7

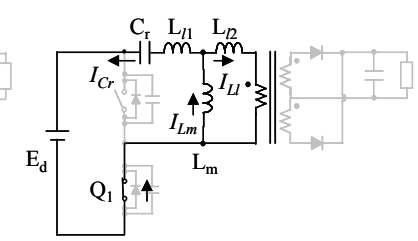

(h) State8
Fig. 3 Equivalent circuits and operation states

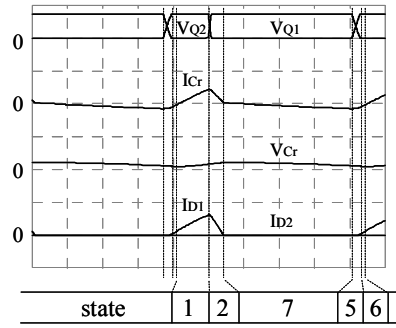

(a) Mode I

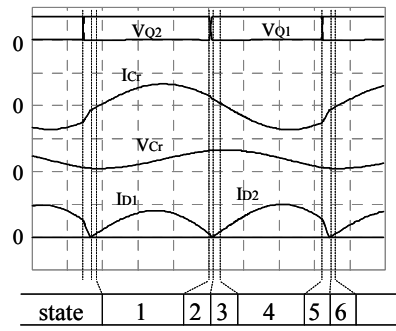

(c) Mode III (b) Mode II

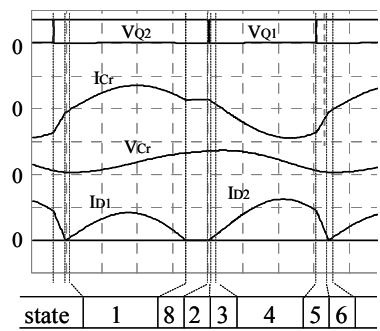

(d) Mode IV

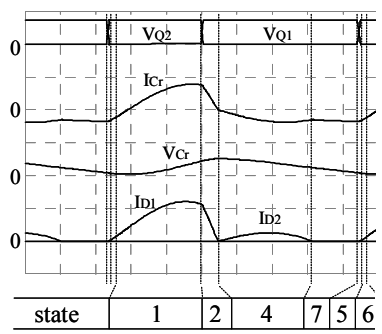

Fig. 4 Operation modes 


\section{POWER EFFICIENCY IMPROVEMENT}

A. Power loss analysis by focusing on the switching devices

Fig. 5 shows the power efficiency characteristic of this converter. The experimental conditions are as follows:

Output voltage $E_{d}$ of $P F C=360 V$, Output voltage $V_{o}=24 \mathrm{~V}$, Output current $\mathrm{I}_{\mathrm{o}}=0.5 \mathrm{~A}-6.2 \mathrm{~A}$, Output Rating $\mathrm{P}_{\mathrm{o}}$ (typ.) $=144 \mathrm{~W}$, Resonant Capacitor $\mathrm{C}_{\mathrm{r}}=22 \mathrm{nF}$, Resonant Inductance $\mathrm{L}_{\mathrm{r}}=320 \mathrm{uH}$, Magnetizing Inductance $\mathrm{L}_{\mathrm{m}}=1.8 \mathrm{mH}$, Winding ratio of $\mathrm{T}_{\mathrm{r}} \mathrm{N}_{\mathrm{P} 1}$ : $\mathrm{N}_{\mathrm{S} 1}\left(=\mathrm{N}_{\mathrm{S} 2}\right): \mathrm{N}_{\mathrm{P} 2}: \mathrm{N}_{\mathrm{P} 3}=59: 8: 5: 6$

To improve power efficiency from the light load to the rated load, power losses in the switching devices at $25 \%, 50 \%, 75 \%$ and $100 \%$ of the rated load are analyzed.

At first, loss $\mathrm{E}_{\mathrm{D} \boldsymbol{n}}(\boldsymbol{n}=1,2)$ of diode $\mathrm{D}_{1}$ and $\mathrm{D}_{2}$ consist of conductive loss $\mathrm{E}_{\mathrm{conD} \boldsymbol{n}}(\boldsymbol{n}=1,2)$ of diode and switching loss $\mathrm{E}_{\mathrm{swD} \boldsymbol{n}}(\boldsymbol{n}=1,2)$ of diode. And they are given as:

$$
\begin{aligned}
& E_{D \boldsymbol{n}}=E_{c o n D \boldsymbol{n}}+E_{s w D \boldsymbol{n}} \\
& E_{c o n D \boldsymbol{n}}=V_{F D \boldsymbol{n}} \cdot I_{D \boldsymbol{n}} \\
& E_{s w D \boldsymbol{n}}=E_{o n D \boldsymbol{n}}+E_{t r r D \boldsymbol{n}}
\end{aligned}
$$

where, $\mathrm{V}_{\mathrm{FD} \boldsymbol{n}}$ and $\mathrm{I}_{\mathrm{D} \boldsymbol{n}}(\boldsymbol{n}=1,2)$ are forward voltage and forward current respectively, and assumed for estimate that $\mathrm{V}_{\mathrm{FD} n}$ are $0.4 \mathrm{~V}$ and $\mathrm{I}_{\mathrm{D} \boldsymbol{n}}$ use the effective current of $\mathrm{D}_{\boldsymbol{n}}(\boldsymbol{n}=1,2)$.

$\mathrm{E}_{\text {onD } \boldsymbol{n}}$ and $\mathrm{E}_{\mathrm{trrD} \boldsymbol{n}}$ are turn-on loss and reverse recovery loss respectively.

Next, loss $\mathrm{E}_{\mathrm{Q} \boldsymbol{n}}(\boldsymbol{n}=1,2)$ of switch $\mathrm{Q}_{1}$ and $\mathrm{Q}_{2}$ are given as:

$$
E_{Q n}=\left(I_{Q n}\right)^{2} \cdot R_{D S o n Q n}+E_{s w Q n}
$$

where, $\mathrm{R}_{\mathrm{DSonQ} \boldsymbol{n}}$ are resistance of MOSFET during turn on and assumed $0.5 \Omega$. $\mathrm{I}_{\mathrm{Q} n}$ use the effective current of $\mathrm{Q}_{n}$. The switching loss $\mathrm{E}_{\mathrm{swQ} \boldsymbol{n}}$ of MOSFET which consists of loss $\mathrm{E}_{\mathrm{onQ} \boldsymbol{n}}$ at turn-on and loss $\mathrm{E}_{\mathrm{offQ} n}$ at turn-off are given as:

$$
E_{s w Q n}=E_{o n Q n}+E_{o f f Q n}
$$

Because of this converter achieves ZVS and ZCS at the point of turn-on of $\mathrm{Q}_{1}$ and $\mathrm{Q}_{2}, \mathrm{E}_{\mathrm{onQ} \boldsymbol{n}}$ are negligible. Therefore, (5) is simplified as:

$$
E_{S w Q n}=E_{o f f Q n}
$$

In addition, the period of state 3 and state 6 in Fig. 2, although current through the body-diode of MOSFET generates the loss before $\mathrm{Q}_{1}$ or $\mathrm{Q}_{2}$ turns-on, these periods are short so this loss is assumed negligible.

Fig. 6 shows the estimated power loss and the power loss ratio of the switching devices. In this figure, an item of "Other" consists of other loss (e.g. loss of transformer, conductive loss of PC board) except for switching device.

It can be seen in Fig. 6 that the loss of diodes in secondary side occupies over $50 \%$ of total loss under all load condition.

Fig. 7 shows the specifics of power loss in diodes. It is found that the main loss of diodes is almost conductive loss.

Furthermore, in Fig. 6 and 7, it is confirmed that the loss of $\mathrm{D}_{1}$ is the most significant under the load condition from $25 \%$ to $75 \%$ of the rated load.

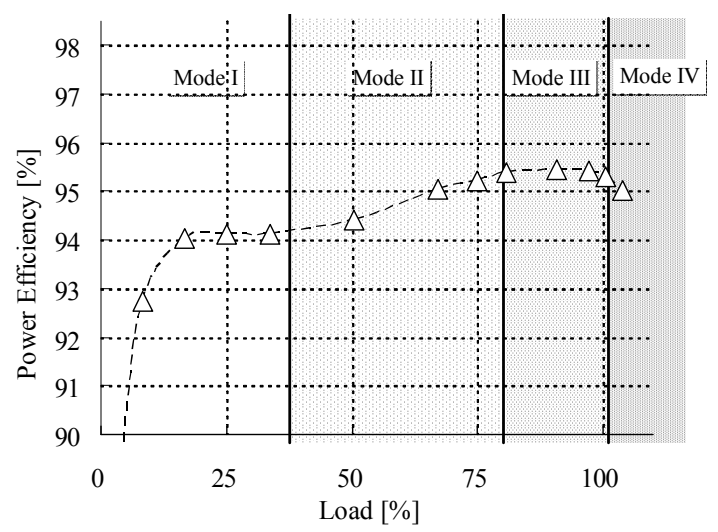

Fig. 5 Power efficiency characteristic

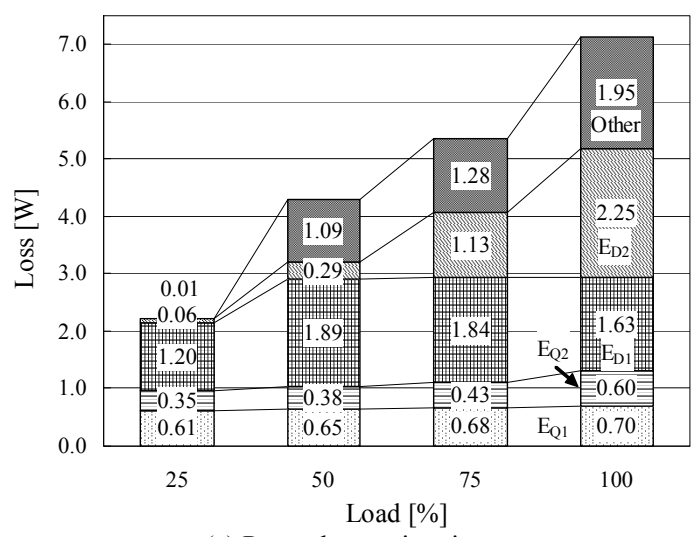

(a) Power loss estimation

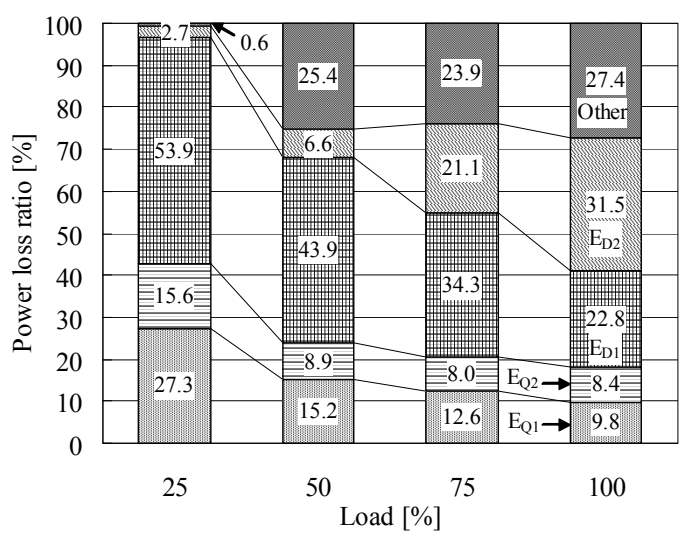

(b) Power loss ratio

Fig. 6 Power loss

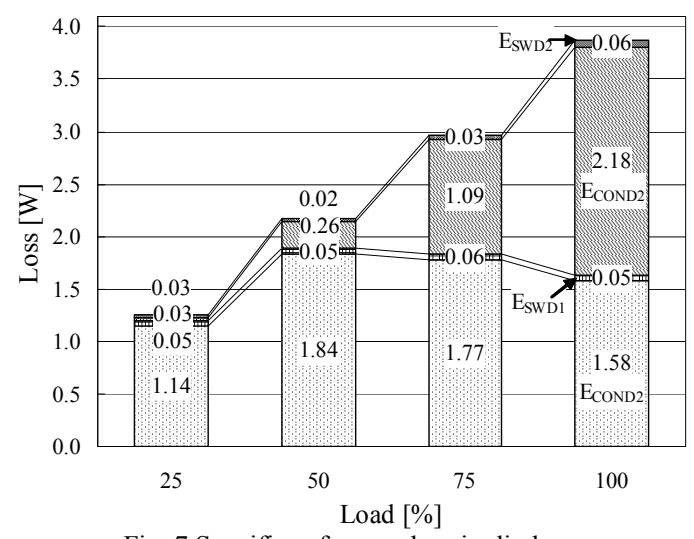

Fig. 7 Specifics of power loss in diodes 


\section{B. Power efficiency improvement using synchronous rectifier}

Generally, current resonant type DC-DC converter employs PFM control and the duty ratio of switch is $50 \%$ regardless of load condition. Therefore the current of diodes in the secondary sides are symmetric. On the other hand, in this proposed converter, the duty ratio of switch Q1 is varied with the load condition. Because of this reason, the current in the secondary sides through $\mathrm{D}_{1}$ and $\mathrm{D}_{2}$ becomes asymmetric. In Fig. 8, during Mode I and Mode II, the current through $\mathrm{D}_{1}$ is higher than that of $\mathrm{D}_{2}$. Meanwhile the current through $\mathrm{D}_{2}$ is higher during Mode IV. By reducing the power loss of $\mathrm{D}_{1}$, improvement of power efficiency in wide range of load is expected.

It is known that adopting synchronous rectifier to reduce power loss of diodes.

Fig.9 shows circuit configuration of synchronous rectifier. In this circuit, diode $\mathrm{D}_{1}$ is replaced with MOSFET $\mathrm{Q}_{\mathrm{S} 1}$. Comparator detects direction of the current by sensing voltage between Drain and Source of $\mathrm{Q}_{\mathrm{S} 1}$. The same circuit configuration is applied to replace $\mathrm{D}_{2}$ with $\mathrm{Q}_{\mathrm{s} 2}$. A power for the comparator and the driver in this circuit is supplied from additional winding on secondary side.

Fig.10 shows power loss characteristics and Fig.11 shows improved power efficiency characteristics. In these figures, only one side of $\mathrm{D}_{1}$ or $\mathrm{D}_{2}$ was replaced with the synchronous rectifier to confirm its effect. It is confirmed in Fig. 10 that the power loss at the rated load reduces $15 \%(7.13 \mathrm{~W}$ to $6.06 \mathrm{~W})$ in the case of replacing $\mathrm{D}_{1}$, and $19 \%(7.13 \mathrm{~W}$ to $5.78 \mathrm{~W})$ in the case of replacing $\mathrm{D}_{2}$. And it is found in Fig. 11 that power efficiency at the rated load are $96.0 \%$ and $96.2 \%$ when replacing $\mathrm{D}_{1}$ and $\mathrm{D}_{2}$ respectively. Regarding at the rated load, changing $D_{2}$ is effective to improve power efficiency. But considering wide range from the light load to the rated load, changing $\mathrm{D}_{1}$ is more effective.

As a result, it is seen in Table 1 that maximum power efficiency achieves $96.3 \%$ and the average efficiency is $95.5 \%$ by adopting the synchronous rectifier to $\mathrm{D}_{1}$.

The details of control method and optimization of synchronous rectifier will be reported in our next paper.

\section{CONCLUSION}

This paper is conclude as follows,

(1) This converter is controlled by a combination of selfoscillation and a separated oscillation.

(2) This converter has eight states and four operating modes.

(3) In this converter, the loss of diodes in secondary side occupies over $50 \%$ of total loss.

(4) The current in the secondary sides through $\mathrm{D}_{1}$ and $\mathrm{D}_{2}$ becomes asymmetric because the duty ratio of switch $\mathrm{Q}_{1}$ is varied with the load condition.

(5) The power loss at the rated load reduces $15 \%$ in case of adopting $\mathrm{Q}_{\mathrm{S} 1}$, and $19 \%$ in the case of adopting $\mathrm{Q}_{\mathrm{S} 2}$.

(6) Considering wide range from the light load to the rated load, adopting the synchronous rectifier to D1 is more effective and maximum power efficiency achieves $96.3 \%$ and the average efficiency is $95.5 \%$.

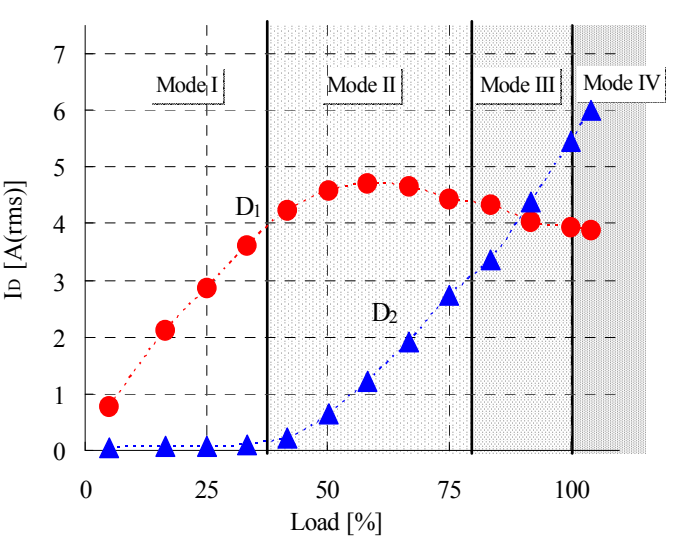

Fig. 8 The current characteristics of Diodes

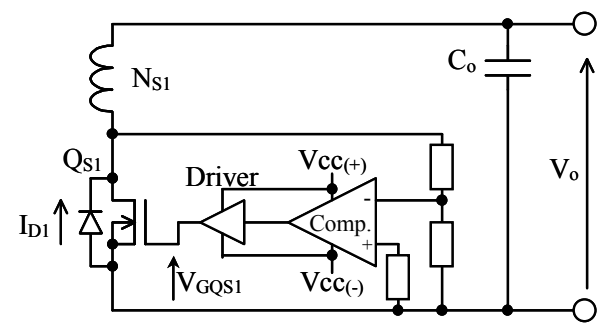

Fig. 9 Circuit configuration of synchronous rectifier

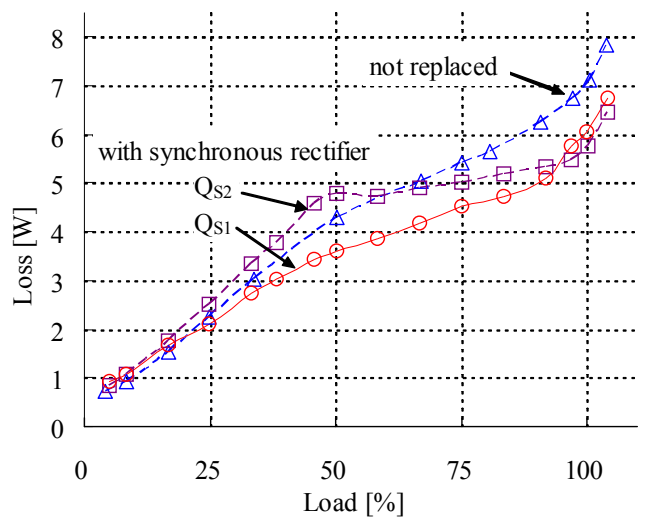

Fig. 10 Power loss characteristics

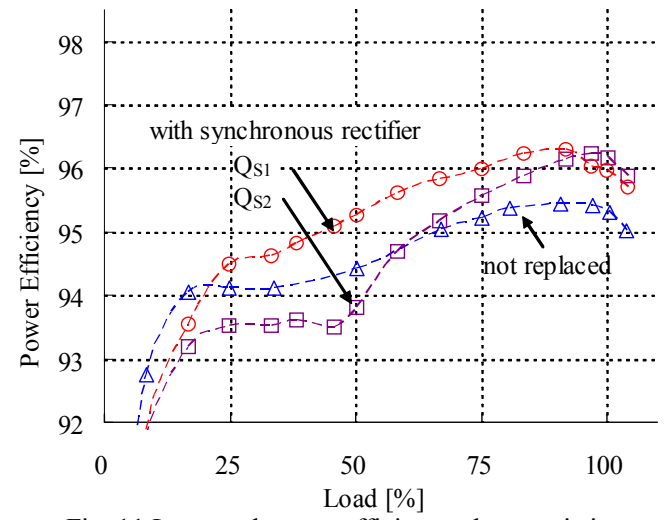

Fig. 11 Improved power efficiency characteristics

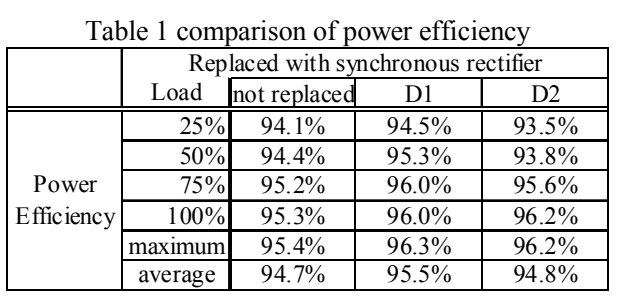




\section{REFERENCES}

[1] M. Gekinozu, K. Kuroki, K. Mori, T. Fujita "Self-oscillated type current resonant DC/DC converter", IEICE Technical Report, EE99-58, pp.33-38. 2002.

[2] Y. Nishikawa, T. Nozawa, S. Igarashi, K. Kuwahara, N. terasawa "Multioscillated Current Resonant Converter", Annual Conference Record of EEEJ, Vol.4, pp.157-158, 2002.

[3] Y. Nishikawa, T. Nozawa, S. Igarashi, K. Kuwahara, N. Nozawa, H. Ota "A control method that reduce the conversion loss at a light load", Annual Conference of Japan, Industry Application Society, pp.631-632, 2002.

[4] R.Araki, O. Matsuo, H. Ota, M. Tuji, Y. Ishizuka, H. Matsuo "Static Analysis of Multi-Oscillated Current Resonant Type DC-DC Converter", IEICE Technical Report, EE2006-31, pp13-18, 2006.

[5] N. Higashi, R. Araki, O. Matsuo, H. Ota, Y. Ishizuka, H. Matsuo "MultiOscillated Current Resonant Type DC-DC Converter", IEICE General Conference, pp.S-45-46, 2007.

[6] O. Matsuo, H. Matsuo, Y. Ishizuka, H. Ota "Analysis of a New Multi-Oscillated Current Resonant Type DC-DC Converter”, IEEE INTELEC’07, pp.348-354, 2007.

[7] T. Sato, R. Araki, H. Ota, N. Higashi, Y. Ishizuka, H. Matsuo "Power Efficiency Analysis of a Multi-Oscillated Current Resonant Type DCDC Converter", IEEE PESC'08, pp.1646-1650, 2008. 